\title{
INFLUÊNCIA DA REDUÇÃO DO TAMANHO DE PARTÍCULAS NA TAXA DE HIDRÓLISE DE ESGOTO BRUTO DOMÉSTICO
}

\author{
INFLUENCE OF PARTICLE SIZE REDUCTION ON THE HYDROLISIS \\ RATE OF DOMESTIC RAW SEWAGE
}

\begin{abstract}
ANA RAQUEL TEIXEIRA
Doutora em Saneamento, Meio Ambiente e Recursos Hídricos Civil pela Escola de Engenharia da UFMG

\section{Carlos Augusto de Lemos Chernicharo}

Professor Associado do Departamento de Engenharia Sanitária e Ambiental da UFMG

SÉRGIO FRANCISCO AQUINO

Professor do Departamento de Química, Universidade Federal de Ouro Preto - UFOP
\end{abstract}

\author{
Recebido: 04/03/08 Aceito: 27/09/08
}

\section{RESUMO}

O trabalho teve por objetivo avaliar as alterações nas taxas de conversão do material particulado do esgoto bruto doméstico, após passar por uma unidade de pré-tratamento que utilizou o peneiramento forçado através de malhas metálicas com aberturas de 1,0 e 0,5 mm como estratégia para reduzir o tamanho médio das partículas. Os resultados mostraram que o peneiramento forçado e a redução do tamanho das partículas presentes no esgoto bruto não foram suficientes para aumentar as taxas de hidrólise do material particulado, uma vez que as constantes de hidrólise para o esgoto bruto e peneirado, estimadas pela relação cinética de primeira ordem, analisando o parâmetro sólidos suspensos voláteis, apresentaram valores semelhantes, da ordem de $0,0492 \pm 0,0146 \mathrm{~d}^{-1}$, para o esgoto bruto, e de $0,0472 \pm 0,0079 \mathrm{~d}^{-1}$ e $0,0470 \pm 0,0117 \mathrm{~d}^{-1}$, para o esgoto bruto peneirado nas malhas de 1 e $0,5 \mathrm{~mm}$, respectivamente.

PALAVRAS-CHAVE: Degradação anaeróbia, hidrólise, esgoto doméstico, pré-tratamento, peneiramento forçado.

\begin{abstract}
The work aimed at assessing the changes in the particulate material conversion rates of domestic raw sewage, after passing through a pre-treatment unit that used the forced sieving through metallic sieves with apertures of 1.0 and $0.5 \mathrm{~mm}$ as strategy to reduce particles' size. The results indicated that the forced sieving and the reduction of particle size were not enough to increase the particulate material hydrolysis rates, since the hydrolysis constants for the raw and sieved sewage, estimated by the first order relation kinetics, analyzing the volatile suspended solids parameter, had similar values, in order of $0.0492 \pm 0.0147 \mathrm{~d}^{-1}$, for the raw sewage, and of $0.0472 \pm 0.0079 d^{-1}$ and $0.0470 \pm 0.00117 d^{-1}$, for the raw sewage sieved in metallic sieves with apertures of 1.0 and $0.5 \mathrm{~mm}$, respectively.
\end{abstract}

KEYWORDS: Anaerobic degradation, domestic sewage, forced sieving, hydrolysis, pre-treatment.

\section{INTRODUÇÃO}

A primeira fase no processo de degradação anaeróbia consiste na hidrólise de materiais particulados complexos (polímeros), transformando-os em compostos solúveis mais simples (moléculas menores), os quais podem atravessar as paredes celulares das bactérias fermentativas, uma vez que as bactérias não são capazes de assimilar a matéria orgânica particulada (macromoléculas). Esta conversão de materiais particulados em materiais solúveis é conseguida através da ação de exoenzimas excretadas pelas bactérias fermentativas hidrolíticas.
No caso de tratamento de efluentes, os processos de hidrólise sintetizam todos os mecanismos que tornam o substrato lentamente biodegradável disponível para as bactérias. Portanto, a hidrólise pode ser diferenciada em dois segmentos: i) hidrólise do substrato primário da qual a matéria orgânica presente no efluente é quebrada; ii) hidrólise do substrato secundário que refere-se à quebra dos compostos produzidos pela célula (substâncias liberadas pelas bactérias durante o metabolismo ou partículas produzi-das durante o decaimento endógeno) (Morgenroth et al, 2002).

A elevada presença de materiais particulados no afluente pode difi- cultar a hidrólise destes compostos, limitan-do a degradação anaeróbia, o que demandaria maiores tempos de detenção hidráulica (TDH) para a completa solubilização da matéria orgânica. Se a matéria orgânica a ser hidrolisada apresenta-se em partículas menores, estas serão teoricamente mais facilmente hidrolisadas, favorecendo as etapas seguintes do processo de digestão anaeróbia. Portanto, a hidrólise pode ser, para alguns compostos particulados, a etapa limitante da degradação anaeróbia (Eastman \& Ferguson, 1981;van Haandel \& Lettinga, 1994; Zeeman \& Sandes, 2001; Vavilin et al, 2001). 
Elmitwalli et al (2001) afirmam que, em reatores anaeróbios, as partículas serão convertidas pela hidrólise depois de serem fisicamente removidas por adsorção, sedimentação ou aderidas ao leito de lodo. Conseqüentemente, requer-se maiores TDHs para a completa solubilização da matéria orgânica em sistemas de tratamento de efluentes com elevadas concentrações de sólidos suspensos.

A hidrólise, sob o ponto de vista químico, significa a quebra de longas cadeias moleculares através de reações com a água. Biologicamente, a hidrólise ocorre através da influência das enzimas especializadas na catálise de reações. Portanto, são reações sensíveis uma vez que fatores externos podem alterar a velocidade das reaçóes e os microorganismos envolvidos apresentam a sua atividade biológica em faixas restritas de algumas variáveis, como $\mathrm{pH}$ e temperatura. Outros fatores podem alterar o grau e a taxa em que o substrato é hidrolisado, como as características do substrato, a diluição do efluente, a área superficial e distribuição do tamanho das partículas (Zhang et al, 2005). Ainda, conforme Siegert \& Banks (2005), a acumulação de ácidos orgânicos voláteis também contribui para a redução da taxa de hidrólise ou até mesmo para sua inibição em concentraçóes extremamente elevadas.

A relação cinética mais utilizada para descrever o processo de hidrólise é de primeira ordem (Batstone et al, 2002), sendo a taxa de reação diretamente proporcional à concentração do substrato, uma vez que a velocidade de uma reação catalisada por enzimas aumenta conforme a concentração de substrato. À medida que a hidrólise ocorre, a concentração do substrato diminui e, conseqüentemente, a velocidade da reação. De acordo com Eastman \& Ferguson (1981), a função de primeira ordem da hidrólise é uma expressão empírica que reflete o efeito cumulativo de todos os processos e pode ser representada pela seguinte equação:

$\frac{\mathrm{dX}_{\text {hidrolisável }}}{\mathrm{dt}}=-\mathrm{k} \cdot \mathrm{X}_{\text {hidrolisável }}$

sendo:

$\mathrm{X}_{\text {hidrolisável }}$ - concentração de substrato particulado hidrolisável $(\mathrm{g} / \mathrm{L})$

$\mathrm{t}$ - tempo (dias)

$\mathrm{k}$ - constante de hidrólise $\left(\mathrm{dia}^{-1}\right)$

No entanto, mesmo quando são mantidos constantes as condições do reator e o tipo de substrato, diferentes valores da constante de hidrólise $(\mathrm{k})$ podem ser atribuídos devido às diferenças na distribuição do tamanho de partículas do substrato (Zeeman \& Sanders, 2001). Ou seja, se a matéria orgânica a ser hidrolisada apresenta-se em partículas menores, estas serão teoricamente mais facilmente hidrolisadas, aumentando o valor de $\mathrm{k}$.

O trabalho objetivou avaliar a influência da alteração da distribuição do tamanho de partículas (DTP) na taxa de hidrólise do esgoto bruto doméstico.

\section{MATERIAL E MÉTODOS}

\section{Aparato experimental}

O aparato experimental era constituído por uma unidade de peneiramento forçado (UPF) pelo qual passava o esgoto doméstico previamente tratado em nível preliminar (gradeamento médio e desarenadores). Foram utilizadas peneiras com aberturas de $1 \mathrm{~mm}$ e $0,5 \mathrm{~mm}$, dificultando assim a passagem de sólidos de maiores dimensões e forçando a ruptura de partículas que passassem pela peneira.

\section{Teste de hidrólise}

Embora não exista padronização nos testes de hidrólise para efluentes líquidos, diferentes experimentos têm sido desenvolvidos para avaliar os mecanismos e locais de atuação da hidrólise, assim como a influência da hidrólise na utilização do substrato (Morgenroth et al, 2002). Portanto, a metodologia desenvolvida foi baseada no balanço de massa em termos de parâmetros usuais de componentes orgânicos (demanda química de oxigênio - DQO, sólidos suspensos voláteis - SSV e metano- $\mathrm{CH}_{4}$ ), que permitiram quantificar a hidrólise do material particulado presente nos esgotos domésticos bruto e peneirado.

\section{Concentração do material particulado do esgoto bruto doméstico}

Um ponto que pode ser limitante para avaliar a hidrólise do esgoto doméstico é a elevada diluição do mesmo. Ou seja, baixos valores de $\mathrm{DQO}_{\text {PARTICULADA }}$ e SS podem dificultar a análise da cinética da hidrólise. Para tanto, a fração particulada dos efluen- tes domésticos, tanto do esgoto bruto quanto do peneirado, foi concentrada a partir da centrifugação do efluente a $3.500 \mathrm{rpm}$ por 10 minutos. O sobrenadante (fração líquida) era removido e o material concentrado era ressuspendido em uma solução de nutrientes, composta de fósforo, nitrogênio, ferro, enxofre, traços de metais e fonte de alcalinidade, utilizada nos testes de Atividade Metanogênica Específica (AME), descrita por Souto et al. (2007). A concentração dava-se numa relação de $10 \mathrm{~L}$ de esgoto, resultando em $1 \mathrm{~L}$ de substrato.

Com esse procedimento, foi possível a obtenção de um substrato com maior $\mathrm{DQO}_{\text {TOTAL }}$ e menor de $\mathrm{DQO}_{\text {FILTRADA }}$ quando comparado ao esgoto bruto doméstico.

\section{Condições de incubação}

O substrato concentrado (esgoto bruto e peneirado nas malhas de 0,5 e $1 \mathrm{~mm}$ ) foi misturado à um volume de lodo, retirado de um reator UASB (upflow anaerobic sludge blanket - reator anaeróbio de fluxo ascendente e manta de lodo) tratando esgotos domésticos, gerando uma mistura-mãe cuja concentração final de sólidos totais voláteis (STV), correspondente à biomassa, era de 0,56 g STV/L, aproximadamente. A mistura-mãe era, então, incubada a $30^{\circ} \mathrm{C}$, em dois experimentos de batelada distintos:

i) no experimento 1 monitorouse a fase gasosa da degradação, com a quantificação da produção de gás metano em função do tempo, utilizando-se um volume de mistura-mãe de $150 \mathrm{~mL}$;

ii) no experimento 2 monitorouse apenas a fase líquida, avaliando-se o incremento de DQO (total e filtrada) e SSV, em função do tempo. Neste experimento, foram utilizados $400 \mathrm{~mL}$ de mistura-mãe e era retirada uma alíquota de $25 \mathrm{~mL}$ para cada dia de análise.

Os experimentos foram realizados em frascos de vidro, com capacidade volumétrica de $200 \mathrm{~mL}$, para o experimento 1 , e $500 \mathrm{~mL}$, no experimento 2, fechados por septos de borracha, garantindo sua estanqueidade. Para imposição de um ambiente anaeróbio, realizou-se a lavagem da atmosfera do frasco com um gás inerte - uma mistura de nitrogênio e gás carbônico (70 e 30\%, respectivamente). Tal mistura foi adotada para prover alcalinidade e ajudar na manutenção do 
pH estável no início do experimento, quando a atividade das acidogênicas é maior. A presença de gás carbônico no headspace garante que haja ácido carbônico dissolvido e permite a manutenção do sistema tampão ácido carbônico/bicarbonato, conforme a reação $\mathrm{H}_{2} \mathrm{CO}_{3}<=>\mathrm{HCO}_{3}^{-}+\mathrm{H}^{+}$. Uma vez por dia, durante 2 minutos, os frascos eram agitados manualmente. Vale ressaltar que as coletas para análise da fase gasosa e da fase líquida eram coincidentes. Ambos os experimentos foram realizados em triplicata para avaliar a consistência dos resultados obtidos e foram efetuados seis testes de hidrólise distintos.

A Figura 1 representa a metodologia do teste de hidrólise.

Análises da fase gasosa

A fração gasosa era retirada por seringa graduada de vidro esmerilhado, umedecida para minimização da força de atrito entre o êmbolo e o corpo da seringa, e o biogás coletado era injetado em cromatógrafo a gás para quantificação do metano presente. Foi utilizada cola de silicone para vedação dos frascos após a coleta do biogás.

\section{Análises da fase líquida}

As análises de DQO e SS seguiram os procedimentos descritos no Standard Methods for the Examination of Water and Wastewater (AWWA/APHA/WEF, 1998). Ressalva-se que a membrana utilizada para determinação da fração filtrada da DQO e SS apresentava porosidade de $1,2 \mu \mathrm{m}$.

\section{Tempo de incubação}

O tempo de incubação foi uma variável definida a partir dos testes preliminares realizados. De acordo com Ginestet et al. (2002), testes de hidrólise que trabalham com curto período

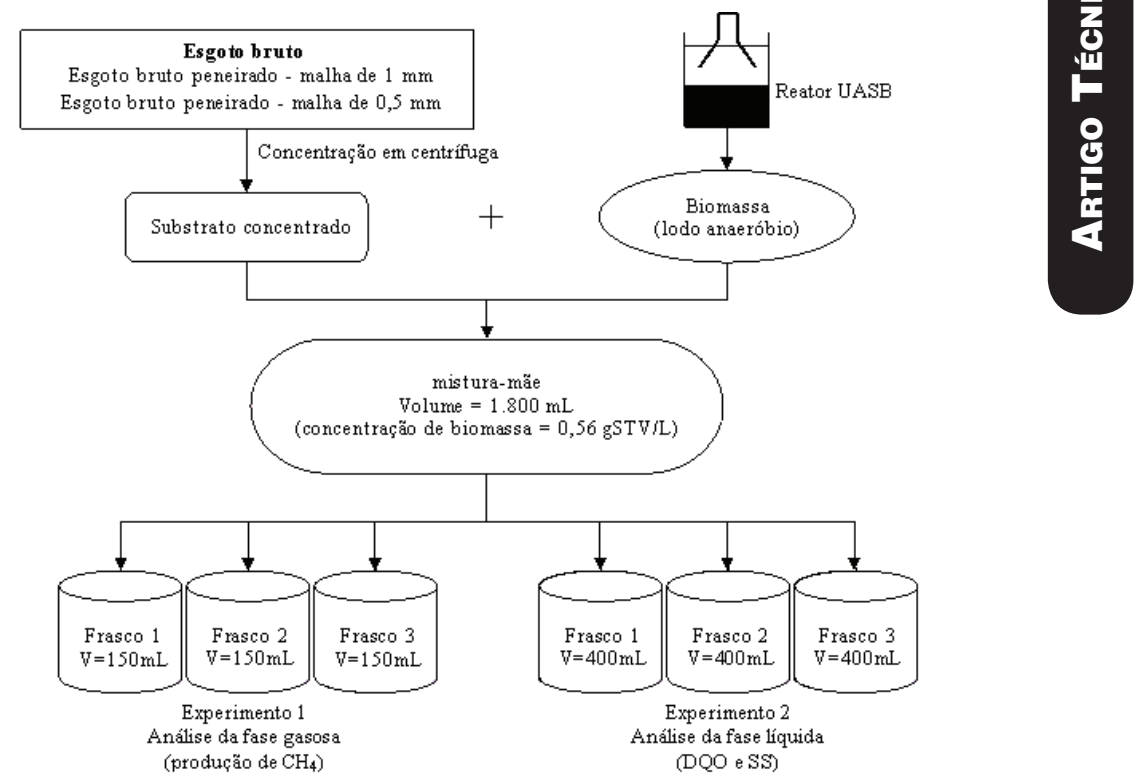

Figura I- Esquema representativo do teste de hidrólise

de incubação e têm a produção de gás como parâmetro indireto de determinação da hidrólise podem apresentar falsos resultados. Isto porque a geração inicial de gás corresponde à conversão da fração rapidamente hidrolisável, ou seja, a matéria orgânica solúvel. Optou-se, portanto, por finalizar os testes quando não houvesse mais produção de gás, o que ocorria em torno de 21 dias de operação, conforme mostraram os primeiros testes.

\section{Modelagem Cinética}

Para modelar a hidrólise, foi utilizada a relação empírica da cinética de $1^{\mathrm{a}}$ ordem devido à sua praticidade, a partir das curvas de variação da massa com o tempo, para cada teste efetuado. Para tanto, três parâmetros foram analisados, segundo os critérios descritos na Tabela 1 .

Três observações são ressaltadas:

i) a massa de DQO $\mathrm{DiLTRADA}_{\text {nos }}$ frascos-reatores, no tempo $\mathrm{T}$, era obtida somando-se a massa aferida e a massa correspondente à produção acumulada de metano $\left(\mathrm{CH}_{4}\right)$, calculada a partir da relação de $1 \mathrm{~g}$ DQO $\approx 394 \mathrm{~mL} \mathrm{CH} 4$, a $30^{\circ} \mathrm{C}$ e 1 atm.

ii) quando a massa inicial $\left(\mathrm{M}_{0}\right)$ de DQO $_{\text {FILTRADA }}$ era muito superior à massa aferida no tempo $T_{2}$, considerouse a massa inicial $M_{2}$, que resultava em maior coeficiente de ajuste da curva $\left(\mathrm{R}^{2}\right)$.

iii) quando a massa inicial $\left(M_{0}\right)$ de DQO $_{\text {PARTICULADA }}$ ou de SSV era muito inferior à massa aferida no tempo $\mathrm{T}_{2}$, considerou-se a massa inicial $\mathrm{M}_{2}$, que resultava em maior coeficiente de ajuste da curva $\left(\mathrm{R}^{2}\right)$.

Ajustados os modelos cinéticos, obtinha-se a constante de hidrólise de cada parâmetro, para cada teste efetuado.

\section{Análises estatísticas}

As análises estatísticas aplicadas para comparar a igualdade da tendência central da constante de hidrólise foram realizadas por meio do programa

Tabela I - Critérios utilizados na modelagem cinética dos testes de hidrólise

\begin{tabular}{|c|c|c|}
\hline Parâmetro modelado & Consideração & Modelo cinético \\
\hline DQO $_{\text {FILTRADA }}$ & $\begin{array}{l}\text { a hidrólise do material particulado gera } \mathrm{DQO}_{\text {FILTRADA }} \text { e é } \\
\text { representada pela curva de produção deste parâmetro }\end{array}$ & $\mathrm{M}_{\mathrm{T}}=\mathrm{M}_{0} \mathrm{XE}^{\mathrm{KT}}$ \\
\hline $\mathrm{DQO}_{\text {PARTICULADA }}$ & $\begin{array}{l}\text { a hidrólise do material particulado é representada pela curva } \\
\text { de decaimento da DQO }\end{array}$ & $M_{T}=M_{0} \times e^{-k T}$ \\
\hline SSV & $\begin{array}{c}\text { a hidrólise do material particulado é representada pela } \\
\text { curva de decaimento dos SSV }\end{array}$ & $M_{T}=M_{0} \times e^{-k T}$ \\
\hline
\end{tabular}

Legenda: $\mathrm{M}_{\mathrm{T}}$ - massa aferida no tempo $\mathrm{T}(\mathrm{mg}) ; \mathrm{M}_{0}$ - massa inicial $(\mathrm{mg}) ; \mathrm{k}$ - constante de hidrólise $\left(\mathrm{d}^{-1}\right) ; \mathrm{T}-$ tempo $(\mathrm{d})$. 
computacional Statistica - versão 6.0. $\mathrm{O}$ teste não paramétricos utilizado foi o teste de Kruskal-Wallis ANOVA e teste de medianas, que permitem uma comparação simultânea entre um grupo de amostras independentes e a verificação de qual constante cinética foi diferente.

\section{RESULTADOS E DISCUSSÃO}

Os resultados obtidos por Teixeira et al (2005) mostram que, após a passagem do esgoto bruto pela peneira com malha de $1 \mathrm{~mm}$, houve um aumento da porcentagem de partículas com diâmetros entre 1,8 e $30 \mu \mathrm{m}$, e conseqüente diminuição da porcentagem de partículas com diâmetros maiores $(50 \mu \mathrm{m})$, diferenciando, assim, os efluentes no que tange à distribuição de tamanho de partículas.

A Tabela 2 apresenta um resumo dos valores aferidos dos parâmetros de SSV e DQO dos efluentes concentrados sem adição do inóculo (o que foi denominado como mistura-mãe), no início de cada um dos seis testes de hidrólise. Vale ressaltar que eram três amostras: esgoto bruto (EB) e bruto peneirado na malha de $1 \mathrm{~mm}(\operatorname{EBp} 1 \mathrm{~mm})$ e de $0,5 \mathrm{~mm}$ (EBp 0,5mm). Observa-se que foi atingindo o objetivo de concentrar o material particulado orgânico dos efluentes, obtendo um substrato com elevadas concentraçóes de $\mathrm{DQO}_{\text {TOTAL }} \mathrm{e}$ SSV, e, adicionalmente, baixa concentração inicial de DQO FILTRAdA $_{\text {. }}$

\section{Modelagem Cinética}

As Figuras 2 a 7 apresentam os modelos cinéticos de $1^{\mathrm{a}}$ ordem, aplicados para cada teste, para descrever a hidrólise do material particulado presente nos efluentes, segundo os parâmetros de

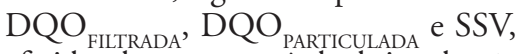
aferidos durante o período de incubação do teste.

Da análise dos resultados, não é possível inferir qual efluente apresentou melhor taxa de hidrólise uma vez que de cada teste tem-se uma conclusão diferenciada dos demais, e, além disso, não seguem o mesmo comportamento no que tange aos parâmetros analisados.

Quando se avalia, no entanto, para o mesmo efluente, os dados gerados, a partir da Figura 8 e da Tabela 3, constata-se que houve baixa variação das constantes de hidrólise estimadas (baixos valores de desvio padrão e variância), podendo representar, de forma aceitável, a média dos resultados dos seis testes. A média e a variação das constantes cinéticas obtidas pelo modelo aplicado às curvas de decaimento de SSV e DQO ${ }_{\text {PARTICULADA }}$ também foram similares, o que indica uma analogia entre as estimativas da taxa de hidrólise da matéria orgânica particulada por estes parâmetros.

Além disso, a constante de hidrólise obtida independe da quantidade inicial de matéria orgânica particulada, uma vez que não são identificadas tendências entre k e a massa inicial destes

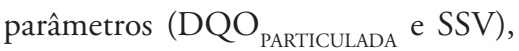
como mostra a Figura 9.

Quando se analisa os resultados obtidos a partir da curva de produção de DQO FILTRADA além de apresentarem valores maiores de desvio padrão e piores ajustes das curvas de tendência (baixos valores de $\mathrm{R}^{2}$ ), a constante de hidrólise estimada tende a aumentar quanto menor a massa inicial aferida (Figura 9). Portanto, mostra-se frágil a correlação da hidrólise com a taxa de produção de DQO FILTRADA .

A Tabela 4 mostra a média das constantes de hidrólise obtidas a partir das curvas de decaimento da massa de DQO $_{\text {particulada }}$ e SSV, porém desconsiderando os valores de $\mathrm{k}$ cujas curvas apresentaram valores de ajuste $\mathrm{R}^{2}$ menores que 0,70 , a saber:

- Esgoto bruto:

$\mathrm{DQO}_{\text {PARTICULADA }}$ $\nabla \mathrm{k}=0,0210 \mathrm{~d}^{-1}$ $\left(\mathrm{R}^{2}=0,37\right.$ - Teste 3)

- Esgoto bruto peneirado - malha de $1 \mathrm{~mm}$ :

$\mathrm{DQO}_{\text {PARTICULADA }} \otimes \mathrm{k}=0,0376 \mathrm{~d}^{-1}$ $\left(\mathrm{R}^{2}=0,64\right.$ - Teste 2)

$\mathrm{DQO}_{\text {PARTICULADA }} \otimes \mathrm{k}=0,0260 \mathrm{~d}^{-1}$

$\left(\mathrm{R}^{2}=0,59\right.$ - Teste 3)

$\mathrm{SSV} \otimes \mathrm{k}=0,0711 \mathrm{~d}^{-1}\left(\mathrm{R}^{2}=0,5071\right.$

- Teste 2)

- Esgoto bruto peneirado - malha de $0,5 \mathrm{~mm}$ :

$\mathrm{DQO}_{\text {PARTICULADA }}$ $\otimes \mathrm{k}=0,0294 \mathrm{~d}^{-1}$ $\left(\mathrm{R}^{2}=0,56\right.$ - Teste 3)

Pode-se notar que os valores de k são muito semelhantes e, quando, aplicadas as análises estatísticas, os testes de hipótese não apontaram diferenças significativas.

Os coeficientes de hidrólise obtidos no estudo foram muito baixos quando comparados aos dados da literatura (Tabela 5), principalmente porque foram estimadas em testes aeróbios, cujas taxas de conversão são maiores que as dos processos anaeróbios.
$\mathrm{O}$ ajuste dos resultados aferidos ao modelo final é apresentado na Figura 10 , desconsiderando os valores dos testes cujas curvas apresentaram $\mathrm{R}^{2}$ inferior a 0,70 , e considerando a relação $\frac{\mathrm{M}_{\mathrm{T}}}{\mathrm{M}_{\mathrm{O}}}$, sendo $\mathrm{M}_{0}=100 \%$.

Mo A dispersão entre os resultados e a curva modelada deve-se a variância dos resultados obtidos durante cada teste de hidrólise, uma vez que o modelo final foi baseado na média dos valores estimados de $\mathrm{k}$.

A Figura 11 mostra a simulação do decaimento de DQO Particulada SSV, durante um teste de hidrólise, com duração de 50 dias e massa inicial de $100 \%$.

A simulação mostra que, em termos de conversão de SSV, não houve diferença entre os efluentes, apresentado a mesma porcentagem de massa final após 50 dias. No caso do parâmetro de $\mathrm{DQO}_{\text {PARTICULADA, }}$ o esgoto bruto apresentou uma taxa de hidrólise ligeiramente superior e, conseqüentemente, uma porcentagem de massa final menor, indicando uma maior conversão da DQO $_{\text {particulada }}$.

Perante o exposto, conclui-se que o efeito do peneiramento forçado na alteração da DTP na faixa de 1,8 a 30 $\mu \mathrm{m}$ não foi suficiente para provocar um benefício na taxa de hidrólise do material particulado presente no esgoto bruto.

Cabe lembrar que o TDH em reatores UASB é da ordem de 7 horas, que hidrolisa apenas 1\% do material particulado, conforme as equaçóes cinéticas obtidas. Por isso, ressalta-se a importância da retenção física do material particulado na manta de lodo por tempo superior ao TDH para que ocorra a hidrólise de quase a totalidade do material particulado presente no efluente. Neste estudo, desconsiderando o regime hidráulico e o fluxo contínuo no reator, para remoção de $80 \%$ do material particulado seria necessário um tempo de residência do lodo de aproximadamente 30 dias, tempo este que usualmente já é usualmente o mínimo observado em reatores UASB com boa capacidade de retenção de biomassa.

\section{CONCLUSÕES}

A redução do tamanho de partículas promovida pela unidade de peneiramento forçado, ao contrário da hipótese levantada, não possibilitou o aumento da taxa de hidrólise do ma- 
Tabela 2 - Parâmetros iniciais dos efluentes concentrados para os testes de hidrólise

\begin{tabular}{|c|c|c|c|c|c|c|c|c|c|}
\hline \multirow[t]{3}{*}{ Teste } & \multicolumn{9}{|c|}{ Parâmetro } \\
\hline & \multicolumn{3}{|c|}{$\begin{array}{c}\text { Concentração de SSV } \\
(\mathrm{g} / \mathrm{L})\end{array}$} & \multicolumn{3}{|c|}{$\begin{array}{c}\text { Concentração de } \mathrm{DQO}_{\text {TOTAL }} \\
(\mathrm{g} / \mathrm{L})\end{array}$} & \multicolumn{3}{|c|}{$\begin{array}{c}\text { Concentração de } \mathrm{DQO}_{\text {PART. }} \\
(\mathrm{g} / \mathrm{L})\end{array}$} \\
\hline & & $1 \mathrm{~mm}$ & & & & & & & \\
\hline 1 & 1,02 & 0,61 & 0,74 & 1,72 & 1,73 & 2,21 & - & - & - \\
\hline 4 & 1,47 & 1,59 & 1,17 & 4,04 & 2,80 & 2,71 & 3,56 & 2,05 & 2,29 \\
\hline 5 & 2,03 & 0,94 & 1,57 & 5,69 & 3,01 & 3,68 & 5,25 & 2,73 & 3,26 \\
\hline 6 & 2,03 & 1,45 & 1,61 & 5,48 & 3,50 & 3,76 & 5,19 & 3,25 & 3,08 \\
\hline
\end{tabular}

Legenda: EB - esgoto bruto; EBp $1 \mathrm{~mm}$ - esgoto bruto peneirado na malha de $1 \mathrm{~mm}$; EBp 0,5mm - esgoto bruto peneirado na malha de $0,5 \mathrm{~mm}$.
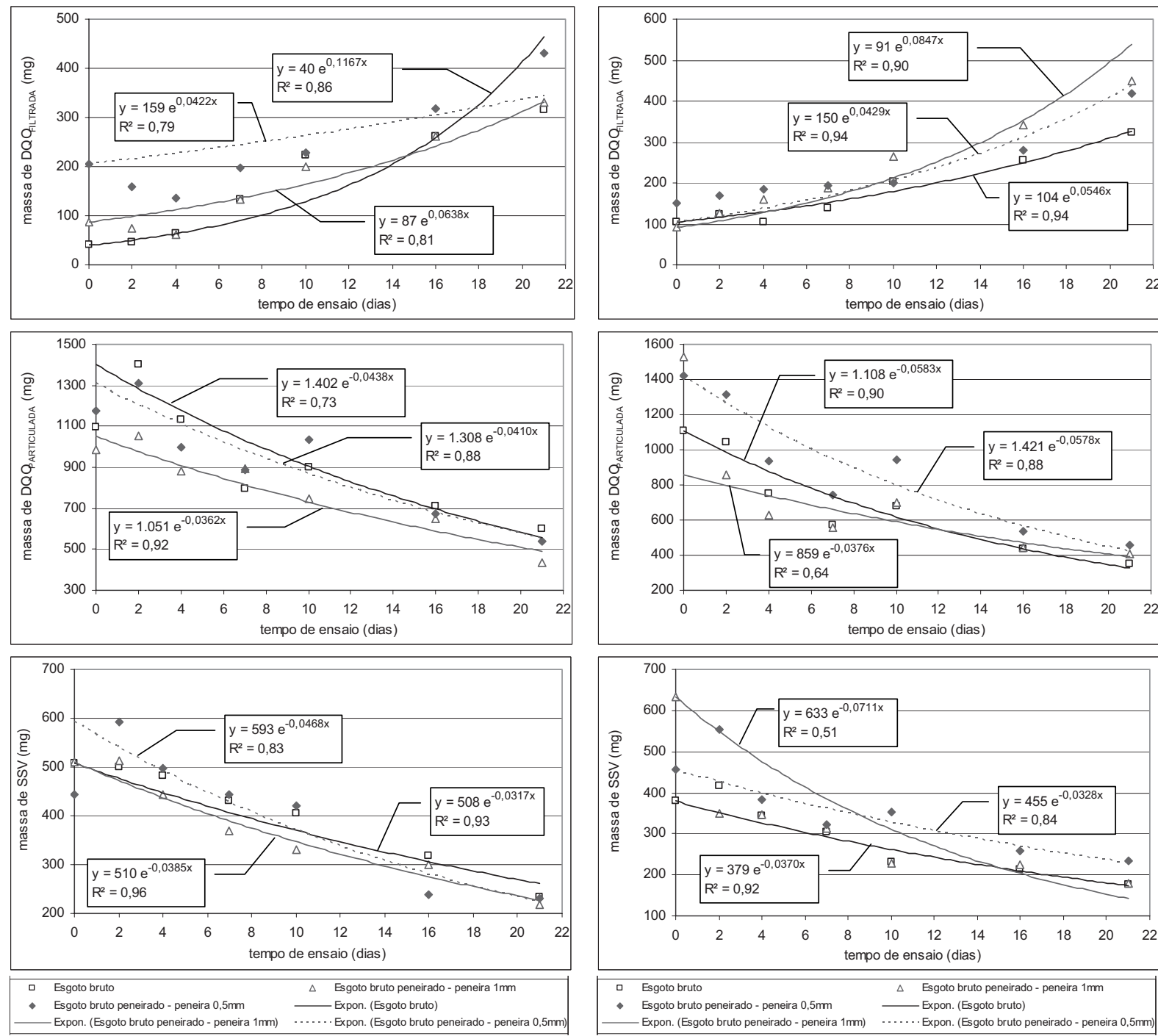

Figura 2 - Modelo cinético da hidrólise para as curvas de produção de DQO ${ }_{\text {FLTRADA }}$ e decaimento de DQO ${ }_{\text {PARTICULADA }}$ e SSV - teste de hidrólise I ( $\left.T=30^{\circ} \mathrm{C}\right)$

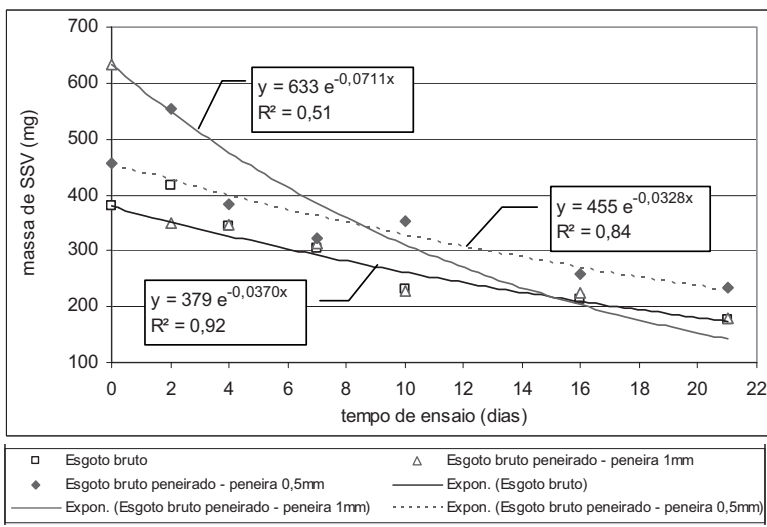

Figura 3 - Modelo cinético da hidrólise para as curvas de produção de DQO ${ }_{\text {FLTRADA }}$ e decaimento de DQO $O_{\text {PARTICULADA }}$ e SSV - Ttste de hidrólise 2 ( $\left(T=30^{\circ} \mathrm{C}\right)$ 

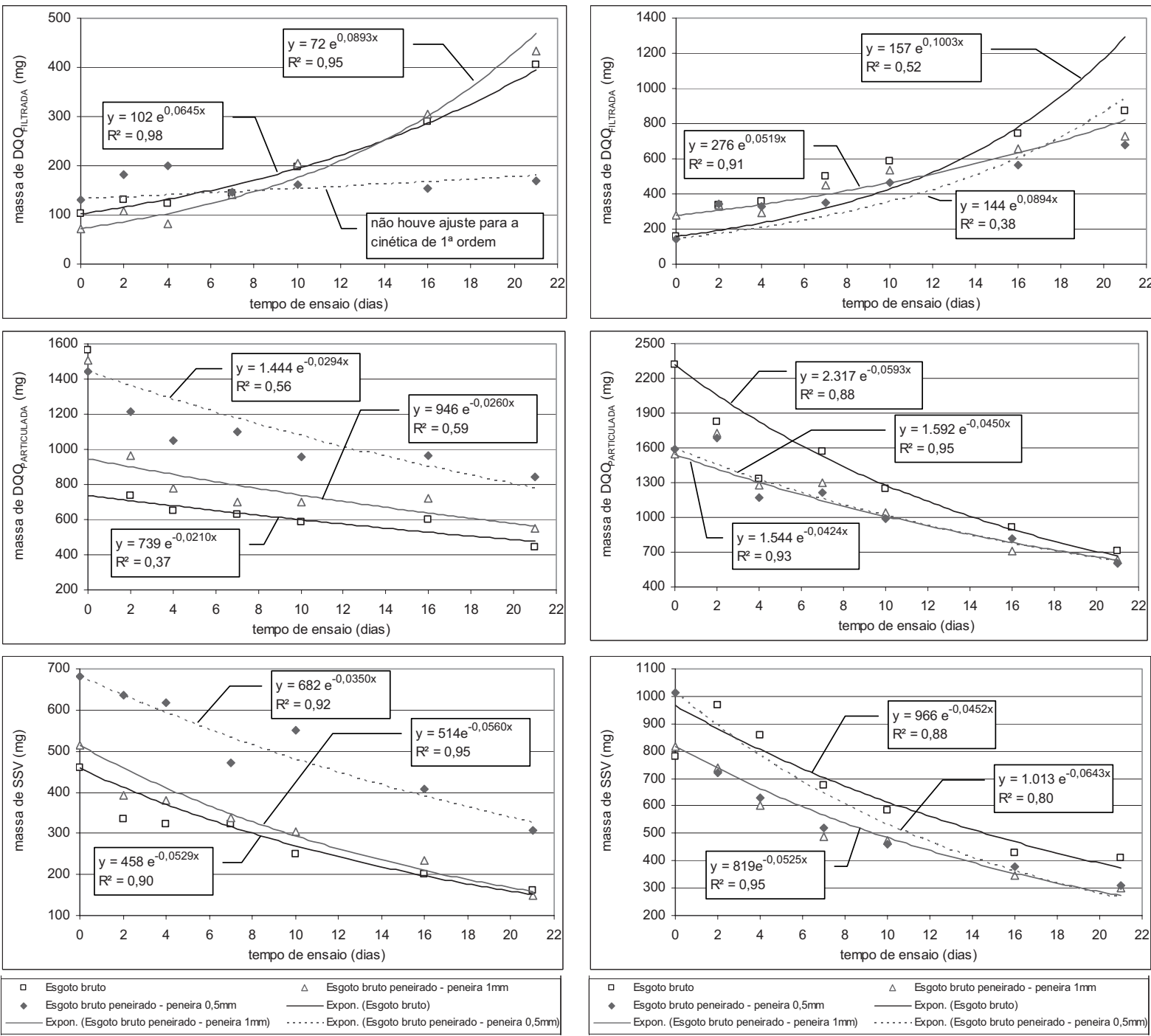

Figura 4 - Modelo cinético da hidrólise para as curvas de produção de DQO ${ }_{\text {FILRADA }}$ e decaimento de DQO hidrólise $3\left(T=30^{\circ} \mathrm{C}\right)$

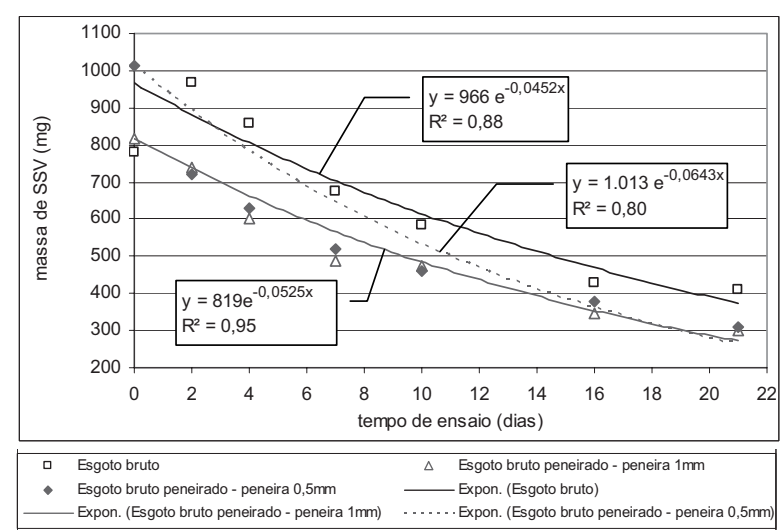

Figura 5 - Modelo cinético da hidrólise para as curvas de produção de DQO ${ }_{\text {FILTADA }}$ e decaimento de DQO hidrólise $4\left(\mathrm{~T}=30^{\circ} \mathrm{C}\right)$ 

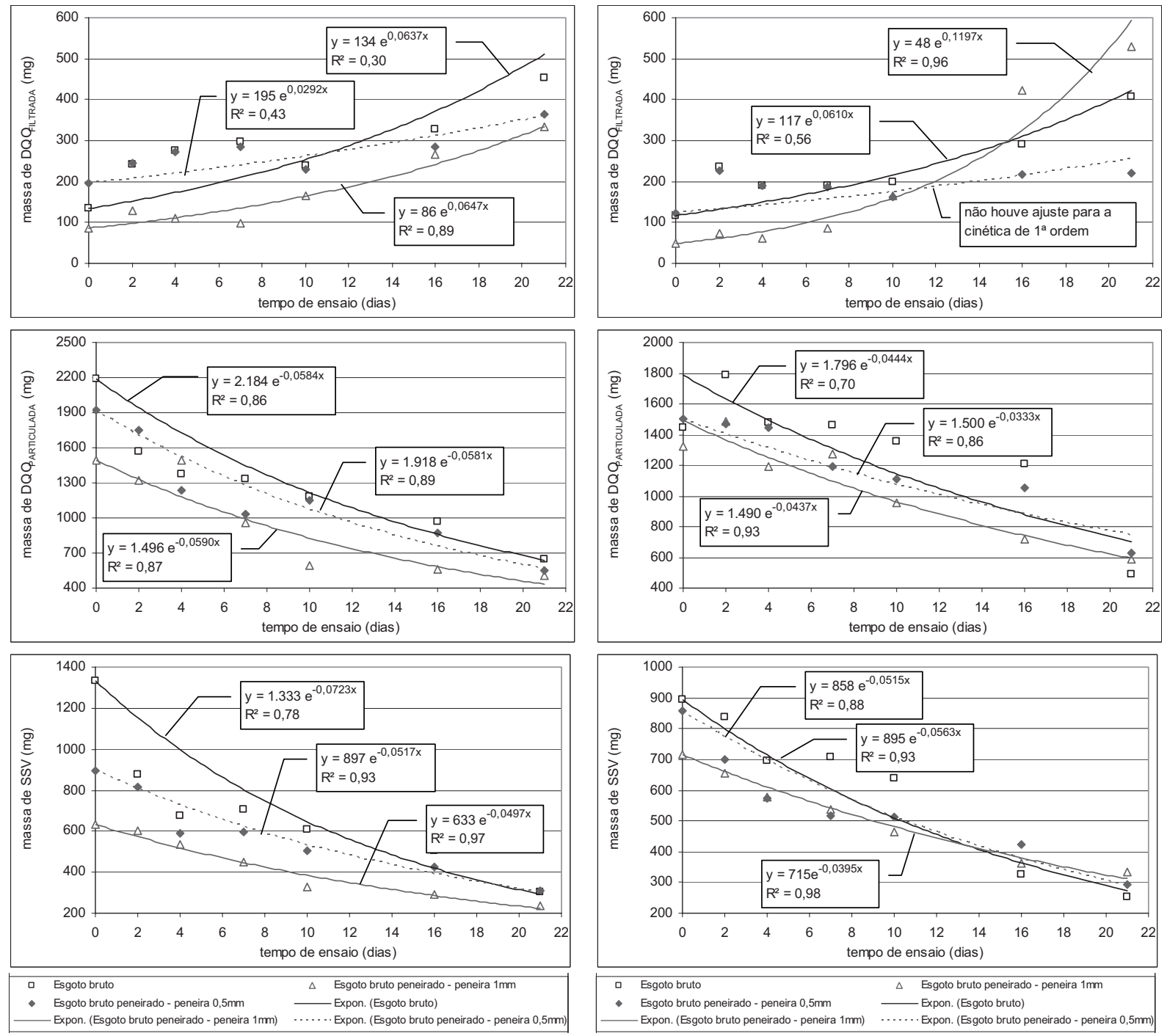

Figura 6 - Modelo cinético da hidrólise para as curvas de produção de DQO ${ }_{\text {FILTRADA }}$ e decaimento de DQO PARTICULADA $_{\text {e SSV - teste de }}$ hidrólise 5 ( $\left.T=30^{\circ} \mathrm{C}\right)$

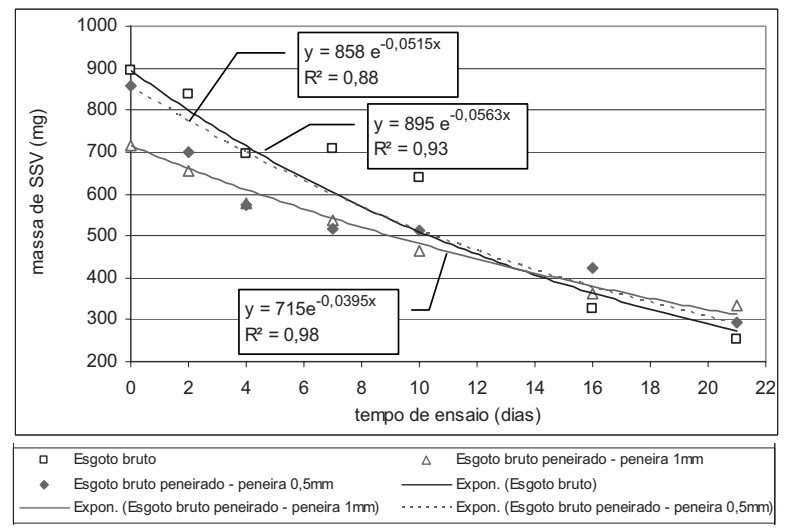

Figura 7 - Modelo cinético da hidrólise para as curvas de produção de DQO ${ }_{\text {FILTRADA }}$ e decaimento de DQO ${ }_{\text {PARTICULADA }}$ e SSV - teste de hidrólise $6\left(T=30^{\circ} \mathrm{C}\right)$ 


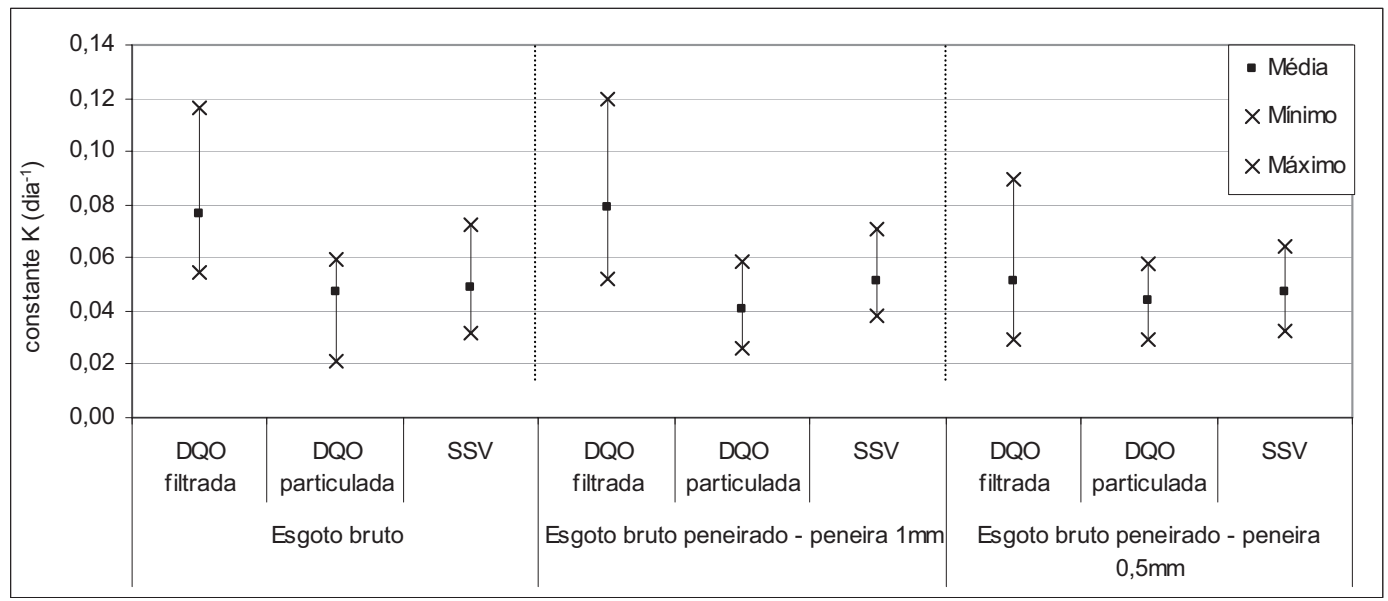

Figura 8 - Valores médio, máximo e mínimo das constantes de hidrólise estimadas para cada efluente analisado, correspondente aos parâmetros avaliados

Tabela 3 - Constantes de hidrólise obtidas para cada teste, média e desvio padrão

\begin{tabular}{|c|c|c|c|c|c|c|c|c|c|}
\hline \multirow[t]{3}{*}{ Teste } & \multicolumn{9}{|c|}{ Constante de hidrólise $\mathrm{k}\left(\mathrm{d}^{-1}\right)$} \\
\hline & \multicolumn{3}{|c|}{ Esgoto bruto } & \multicolumn{3}{|c|}{$\begin{array}{l}\text { Esgoto bruto peneirado } \\
\text { malha de } 1 \mathrm{~mm}\end{array}$} & \multicolumn{3}{|c|}{$\begin{array}{l}\text { Esgoto bruto peneirado } \\
\text { malha de } 0,5 \mathrm{~mm}\end{array}$} \\
\hline & $\mathrm{DQO}_{\text {FILT }}$ & $\mathrm{DQO}_{\text {PART }}$ & SSV & $\mathrm{DQO}_{\text {FILT }}$ & $\mathrm{DQO}_{\text {PART }}$ & SSV & $\mathrm{DQO}_{\mathrm{FILT}}$ & DQO $_{\text {PART }}$ & SSV \\
\hline 1 & 0,1167 & 0,0438 & 0,0317 & 0,0638 & 0,0362 & 0,0385 & 0,0422 & 0,0410 & 0,0468 \\
\hline 2 & 0,0546 & 0,0583 & 0,0370 & 0,0847 & 0,0376 & 0,0711 & 0,0429 & 0,0578 & 0,0328 \\
\hline 3 & 0,0645 & 0,0210 & 0,0529 & 0,0893 & 0,0260 & 0,0560 & - & 0,0294 & 0,0350 \\
\hline 4 & 0,1003 & 0,0593 & 0,0452 & 0,0519 & 0,0424 & 0,0525 & 0,0894 & 0,0450 & 0,0643 \\
\hline 5 & 0,0637 & 0,0584 & 0,0723 & 0,0647 & 0,0590 & 0,0497 & 0,0292 & 0,0581 & 0,0517 \\
\hline 6 & 0,0610 & 0,0444 & 0,0563 & 0,1197 & 0,0437 & 0,0395 & - & 0,0333 & 0,0515 \\
\hline Média & 0,0768 & 0,0475 & 0,0492 & 0,0790 & 0,0408 & 0,0512 & 0,0509 & 0,0441 & 0,0470 \\
\hline DP & 0,0253 & 0,0148 & 0,0146 & 0,0244 & 0,0109 & 0,0120 & 0,0264 & 00121 & 0,0117 \\
\hline Variância & 0,0006 & 0,0002 & 0,0002 & 0,0006 & 0,0001 & 0,0001 & 0,0007 & 0,0001 & 0,0001 \\
\hline $\mathrm{CV}$ & 0,33 & 0,31 & 0,30 & 0,31 & 0,27 & 0,23 & 0,52 & 0,27 & 0,25 \\
\hline
\end{tabular}




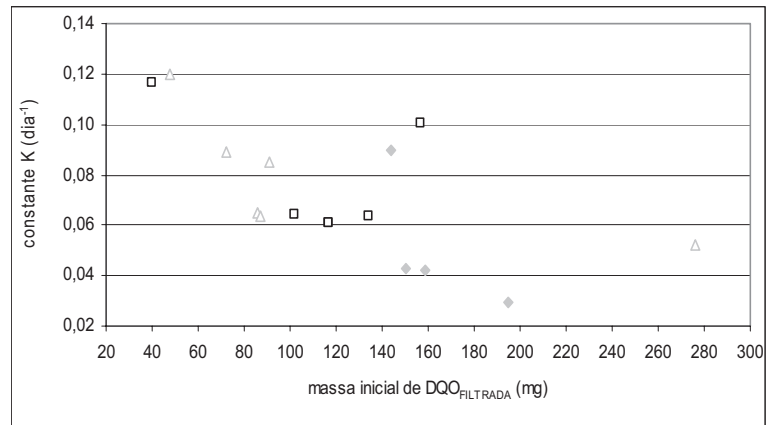

$\square$ Esgoto bruto $\triangle$ Esgoto bruto peneirado - peneira $1 \mathrm{~mm} \triangleq$ Esgoto bruto peneirado - peneira $0,5 \mathrm{~mm}$
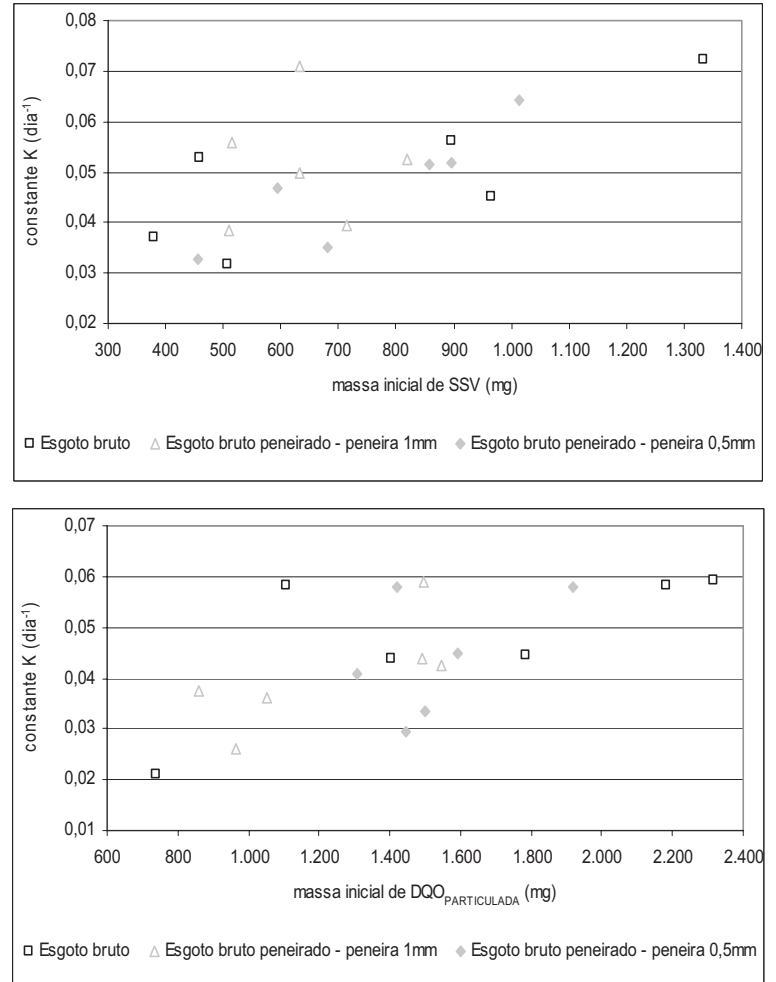

Figura 9 - Variação da constante de hidrólise $k$ com a massa inicial de DQO PARTICULADA SSV e DQO ${ }_{\text {FLTRADA }}$

Tabela 4 - Valor médio da constante de hidrólise $k$ dos esgotos bruto e bruto peneirado (para valores de ajuste $\mathrm{R}^{2}>0,70$ )

\begin{tabular}{ccc}
\hline Efluente & \multicolumn{2}{c}{$\left.\mathrm{k}^{-1}\right)$} \\
& para DQO & \\
& $0,0528 \pm 0,0080$ & $0,0492 \pm 0,0146$ \\
Esgoto bruto & $0,0453 \pm 0,0097$ & $0,0472 \pm 0,0079$ \\
Esgoto bruto peneirado malha de $1 \mathrm{~mm}$ & $0,0470 \pm 0,0108$ & $0,0470 \pm 0,0117$ \\
\hline
\end{tabular}


Tabela 5 - Valores de coeficientes de hidrólise relatados pela literatura

\begin{tabular}{cccc}
\hline Autor(es) & Metodologia & Modelo cinético & $\mathrm{k}$ \\
\hline $\begin{array}{c}\text { Eliosov \& Argaman } \\
(1995)\end{array}$ & Testes de batelada com aeração & Primeira ordem & $0,16{\mathrm{a} 0,20 \mathrm{~d}^{-1}}$ \\
Ginestet et al (2002) & Uso de respirômetro & Primeira ordem & $9 \pm 2 \mathrm{~d}^{-1}$ \\
Okutman et al (2001) & $\begin{array}{c}\text { Testes de batelada com aeração (parcela } \\
\text { sedimentável do esgoto bruto doméstico) }\end{array}$ & Superfície-limitante & $1,2 \mathrm{~d}^{-1}$ \\
\hline
\end{tabular}
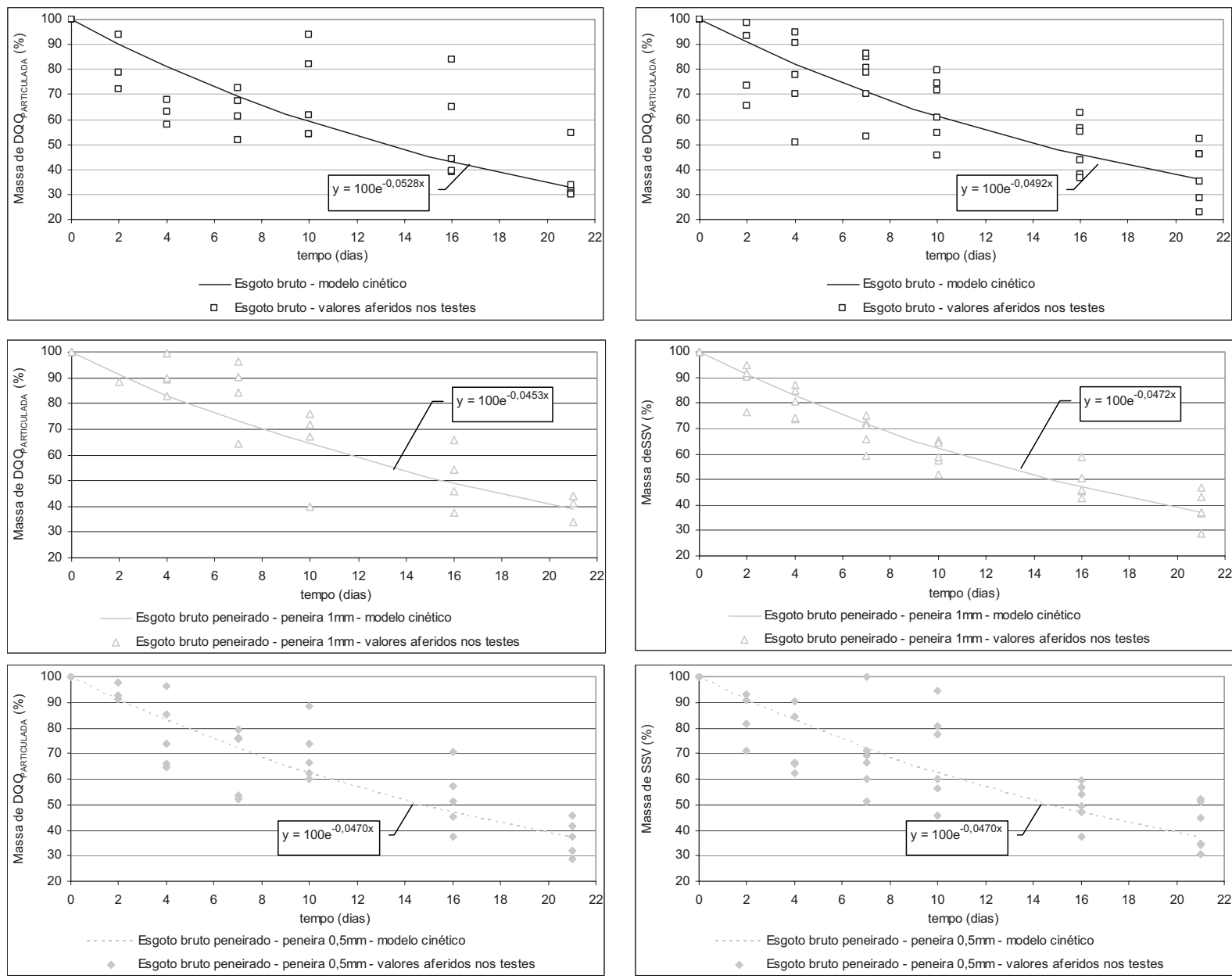

Figura 10 - Ajuste dos resultados aferidos ao modelo cinético final - DQO PARTICULADA $_{\text {e SSV }}$

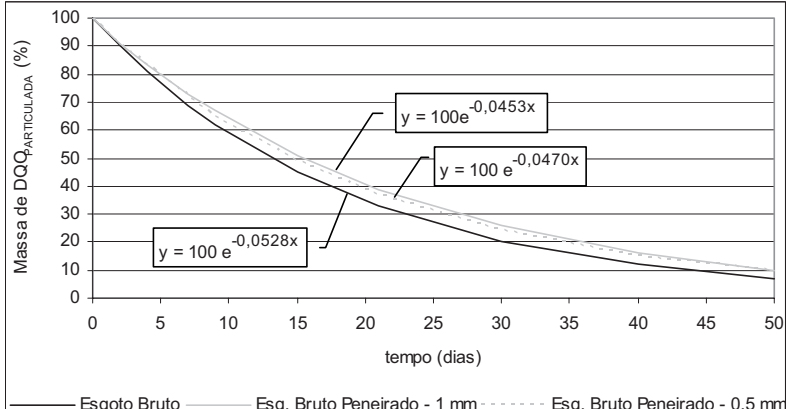

Figura II - Decaimento da massa de DQO

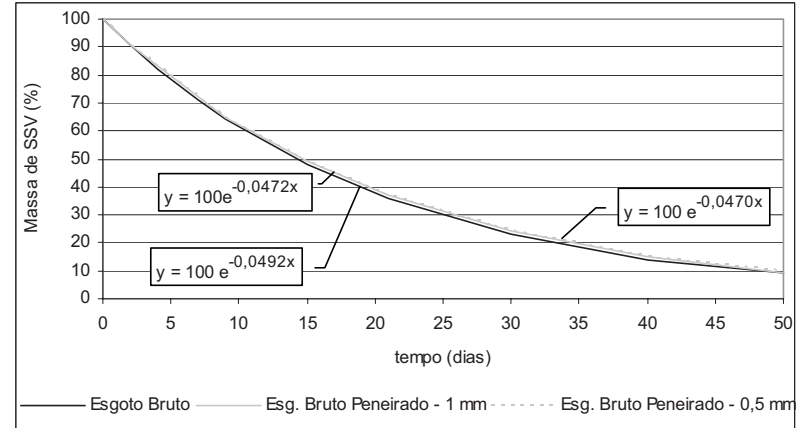

e SSV durante um teste de hidrólise 
terial particulado contido no esgoto, conforme pode-se inferir a partir da semelhança entre as constantes de hidrólise determinadas para os esgotos bruto e bruto peneirado.

A modelagem da cinética da hidrólise através do parâmetro de $\mathrm{DQO}_{\text {FILTRADA }}$ mostrou-se frágil, devido aos maiores valores de desvio padrão, baixos ajustes das curvas de tendência (valores de $\mathrm{R}^{2}$ ) e a aparente interdependência entre os valores de $\mathrm{k}$ e a massa inicial. Quando analisado os

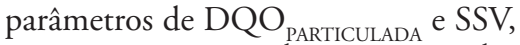
não existiram grandes variações das constantes de hidrólise estimadas pelo modelo cinético.

Quando avaliado o decaimento de $\mathrm{DQO}_{\text {PARTICULADA }}$ a taxa de hidrólise foi ligeiramente maior no esgoto bruto, com taxa de hidrólise de $0,0528 \pm 0,0080 \mathrm{~d}^{-1}$, sendo que os esgotos peneirados na malha de $1 \mathrm{e}$ $0,5 \mathrm{~mm}$ apresentaram, respectivamente, valores de $\mathrm{k}$ de $0,0453 \pm 0,0097 \mathrm{~d}^{-1} \mathrm{e}$ $0,0470 \pm 0,0108 \mathrm{~d}^{-1}$. Já as constantes cinéticas obtidas no modelo aplicado ao decaimento de SSV foram semelhantes para os esgotos bruto, bruto peneirado na malha de $1 \mathrm{~mm}$ e na malha de $0,5 \mathrm{~mm}$, apresentando valores de $0,0492 \pm 0,0146 \mathrm{~d}^{-1}, 0,0472 \pm 0,0079 \mathrm{~d}^{-1} \mathrm{e}$ $0,0470 \pm 0,0117 \mathrm{~d}^{-1}$, respectivamente.

\section{AGRECIMENTOS}

Os autores agradecem aos órgãos fomentadores FINEP/PROSAB, CNPQ e FAPEMIG, pelo financiamento da pesquisa, à COPASA MG, pelo espaço cedido para implantação do aparato experimental, e à Prominas Brasil Equipamentos, por confeccionar e ceder gentilmente as peneiras metálicas utilizadas no estudo.

\section{REFERÊNCIAS}

BATSTONE, D.J.et al. Anaerobic digestion model $n^{\circ}$. 1. Scientific and Technical Report, no. 13. 88p., 2002.

EASTMAN, J.A.; FERGUSON, J.F. Solubilization of particulate organic-carbon during the acid phase of anaerobic-digestion. Journal Water Pollution Control Federation, v. 53, n. 3, p. 352-366, 1981.

ELMITWALLY, T.A. et al. Biodegradability and change of physical characteristics of particles during anaerobic digestion of domestic sewage. Water Research, v. 35, n. 5, p. 1311-1317, 2001.

ELIOSOV, B.; ARGAMAN, Y. Hydrolysis of particulate organics in activated sludge systems. Water Research, v. 29, n. 1, p. 155-163, 1995.
GINESTET, P:; MAISONNIER, A.; SPÉRANDIO, M. Wastewater COD characterization: biodegradability of physico-chemical fractions. Water Science Technology, v. 45, n. 6, p. 89-97, 2002.

OKUTMAN, D.; ÖVEZ, S.; ORHON, D., Hydrolysis of settleable substrate in domestic sewage. Biotechnology Letters, v. 23, n. 23, p. 1907-1914, 2001.

MORGENROTH, E.; KOMMEDAL, R.; HARREMOËS, P. Process and modeling of hydrolysis of particulate organic matter in anaerobic wastewater treatment - a review. Water Science Technology, v. 45, n. 6, p. 25-40, 2002.

SIEGERT, I.; BANKS, C. The effect of volatile fatty acid additions on the anaerobic digestion of cellulose and glucose in batch reactors. Process Biochemistry, v. 40, p. 3412-3418, 2005.

SOUTO, T. F. S.; AQUINO, S. F.; CHERNICHARO, C. A. L. Avaliação da influência das condiçôes de incubação no Teste de Atividade Metanogênica Específica (AME) de lodos anaeróbios. In: $24^{\circ}$ CONGRESSO BRASILEIRO DE ENGENHARIA SANITÁRIA E AMBIENTAL, Anais... Belo Horizonte, 2007.

TEIXEIRA, A. R. et al. Influência do peneiramento forçado do esgoto bruto no desempenho de reator UASB tratando esgoto doméstico. In: $23^{\circ} \mathrm{CON}-$ GRESSO BRASILEIRO DE ENGENHARIA SANITÁRIA E AMBIENTAL, Campo Grande. Anais... Rio de Janeiro: Abes, 2005.

VAN HAANDEL, A.C.; LETTINGA, G. Anaerobic sewage treatment: a practical guide for regions with a hot climate. 1.ed. John Wiley and Sons, 222p. 1994.
VAVILIN, V.A. et al. Simplified hydrolysis models for the optimal design of two-stage anaerobic digestion. Water Research, v.35, n. 17, p. 4247-451, 2001.

ZHANG, B. et al. The influence of $p H$ on hydrolysis and Acidogenesis of kitchen wastes in two-phase anaerobic digestion. Environment Pollution, v. 26, n. 3, p. 329-339, 2005.

ZEEMAN, G.; SANDERS, W. Potential of anaerobic digestion of complex waste (water). Water Science Technology, v. 44, n. 8, p. $115-122,2001$.

Endereço para correspondência:

\section{Carlos Augusto de Lemos \\ Chernicharo}

Departamento de Engenharia

Sanitária e Ambiental - UFMG

Av. do Contorno, 842/7 andar

Centro

30 I I 0-060 Belo Horizonte - MG-

Brasil

Tel: (3I) 3238-I020

E-mail: calemos@desa.ufmg.br 